\title{
Scalability of the Basic Care Model for Very Low Birth Weight Infants and Implementation Research Considerations
}

\author{
Subhashchandra Daga
}

\section{ABSTRACT}

Objectives: To study the scalability of the rural hospital (RH) model of basic newborn care in a general hospital (GH) by including very low birth weight (VLBW) infants, and to assess the implementation aspects.

Study design: Observational

Settings: RH (1988-1992) and General Hospital, (GH) (2010-2013).

Subjects: VLBW infants with birth weight ranging from $1000 \mathrm{~g}$ to 1500 g.

Interventions: (1) RH: Basic care including warmth, feeding, antibiotics, and oxygen (2) GH: Basic plus circulatory care (2010-12), and continuous positive airway pressure (CPAP) support (2013). Mechanical ventilation and surfactant therapy were not available.

Main outcome measure: Mortality

Results: The cumulative mortality (38.5\%) with basic neonatal care in the $\mathrm{RH}$ model declined to $26.6 \%$ at the GH with the addition of circulatory support and a "home-made" CPAP system.

Conclusions: The RH package may be scaled up by adding CPAP and circulatory support to reduce the mortality among VLBW infants. The RH model is scalable horizontally and vertically.

What is already known about this subject?

- Implementation research constitutes a relatively new and underdeveloped field,

- One of the facets of health system research is the implementation research.

- Implementation research aims at bridging the gaps between knowledge and action.

What does this study add?

- Tertiary care center can help in developing basic newborn care at a rural hospital.

- The rural hospital model can be upscaled vertically as well as horizontally.

- Addition of circulatory support and CPAP to basic newborn care can significantly lower neonatal mortality.

How might it impact on clinical practice in the foreseeable future?

The study may encourage tertiary care centers to facilitate the development of basic newborn care centers at the rural hospitals. These centers, in turn, can spread horizontally.

Keywords: Implementation research and newborn care, low-cost newborn care, neonatal mortality, newborn care with limited resources, very low birth weight babies.

\section{INTRODUCTION}

The journal reserves the right to do the final formatting of your paper. The neonatal mortality rate (NMR) was reduced by $49 \%$, from 37 deaths per 1,000 live births in 1990 to 19 in 2016 [1]. Preterm infants account for $35 \%$ of newborn deaths
Published Online: December 7, 2021

ISSN: $2736-5476$

DoI: $10.24018 /$ ejclinicmed.2021.2.6.150

S. Daga*

Emeritus Prof. B.J. Medical College and Sassoon General Hospital, India.

(e-mail: dagasubhash49@gmail.com)

*Corresponding Author
[1]. Therefore, the prevention of preterm birth and improving the care of preterm infants are important. While interventions for the prevention of preterm birth are challenging by themselves, the focus must shift toward interventions that improve the survival of preterm infants. With the inaccuracy in determining the date of conception in low- and middle- 
income countries (LMIC), and in countries where pregnancy tests are not readily available, low birth weight (LBW) may be used as an indicator of prematurity. Of these, the very low birth weight (VLBW) infants typically require more specialized and expensive neonatal intensive care over extended periods, and it may be challenging to implement the high-tech neonatal intensive care model in the LMIC.

This study revisits the earlier data where low-tech and inexpensive interventions were used at a rural hospital (RH) [2] and examines its upscaling at the General Hospital (GH), which is attached to a teaching institution, to examine VLBW mortality. Furthermore, it examines the implementation research (IR) aspects of the program at the RH to assess the process that defined the implementation outcomes [3].

\section{METHODS}

The study was conducted at the General Hospital, Talegaon, between 2010 and 2013. The hospital is attached to a newly opened medical college in a rural area of the Pune district in India. The neonatal intensive care unit (NICU) that was developed also served as a first referral unit (FRU) for nearby PHCs and private maternity homes. The methodology adopted included basic care in line with the Dahanu $\mathrm{RH}$ model [2], as well as circulatory and continuous positive airway pressure (CPAP) support. This study aimed to assess the impact of the approach on VLBW mortality and the issues in its implementation.

Warmth, feeding, and antibiotics, and oxygen administration formed the basic care components. Circulatory support included inotrope and pulmonary vasodilator administration, as indicated. Respiratory support was extended in the form of CPAP. It was delivered by an inexpensive, easy-to-use version of the CPAP delivery system [4], [5]. Vancomycin was used more frequently in the years 2012-13 in the treatment of infants with suspected sepsis, who weighed less than $1500 \mathrm{~g}$. Importantly, the modes of delivery of basic care were identical at the $\mathrm{RH}$ and $\mathrm{GH}$; for example, warm rooms instead of individual warming [6], enteral feeding of human milk [7], IM administration of firstline antibiotics, (ampicillin and gentamicin) and oxygen by headbox. Infants less than $1000 \mathrm{~g}$ were excluded from the study.

Local clinical guidelines formed the basis of management at GH. They were revised periodically, following monthly death audits. Routinely, complete blood counts were performed at the time of admission. In the case of respiratory distress, chest radiography was performed. A portable X-ray machine was available for this purpose. Blood gas analysis, surfactant administration, mechanical ventilation, and mechanical CPAP delivery units were not available. For an average bed-occupancy of 13 infants, there were always two staff nurses on duty. One junior and one senior resident were present per 8-hour shift, guided by three consultants in rotation. All doctors were also responsible for pediatric outpatient and inpatient care. The consultants were also involved in undergraduate and postgraduate teaching.

Labor Room Care also included chlorhexidine application to the umbilical cord stump [8]. The Cesarean rate was around $30 \%$. This study pertains to the admissions and deaths among VLBW infants at the RH (1988-1992) and GH (2010-2013), excluding those weighing less than $1000 \mathrm{~g}$.

\section{A. Ethics}

The ethics committee of MIMER medical college and hospital, Talegaon Dabhade, approved this study, and waived the need for consent from the participants.

\section{B. Patient and Public Involvement}

Patients and public were not directly involved in the design of this study

\section{RESULTS}

The cumulative mortality among VLBW infants was $38.5 \%$ at the RH (Table I). Following the introduction of circulatory support and respiratory support by CPAP [4], [5] at the GH (Table II), the mortality rate declined significantly from $40 \%$ in 2012 to $26.5 \%$ in 2013 .

There were clear and positive answers concerning implementation, identification of the primary subjects for the research, description of what was being implemented, and the definition of the implementation strategy. The questions and answers may be found in the supplementary document.

\begin{tabular}{|c|c|c|}
\hline $\mathrm{C}$ & Admissions (no) & Deaths (\%) \\
\hline $1000-1500$ & 96 & $37(38.5)$ \\
\hline $1520-2000 *$ & 251 & $19(7.5)$ \\
\hline $2020-2500$ & 752 & $13(1.7)$ \\
\hline More than 2500 & 1104 & $8(0.7)$ \\
\hline
\end{tabular}

TABLE II: WeIgHT-Wise Mortality (\%) AT THE GENERAL HosPitAL:

\begin{tabular}{ccccc}
\multicolumn{5}{c}{$2010-2013$} \\
\hline \multirow{2}{*}{ Year } & 2010 & 2011 & 2012 & 2013 \\
& $\mathrm{~A}(\mathrm{D})$ & $\mathrm{A}(\mathrm{D})$ & $\mathrm{A}(\mathrm{D})$ & $\mathrm{A}(\mathrm{D})$ \\
\hline \hline $1000-$ & $36(20)$ & $28(14)$ & $40(16)$ & $45(12) * *$ \\
$1499 \mathrm{~g}$ & $54 \%$ & $50 \%$ & $40 \%$ & $26.6 \%$ \\
$1500-$ & $117(16)$ & $118(15)$ & $69(6)$ & $61(5) * *$ \\
$1999 \mathrm{~g}$ & $13.6 \%$ & $12.8 \%$ & $8.6 \%$ & $8.1 \%$ \\
$2000-$ & $285(8)$ & $332(15)$ & $168(5)$ & $147(5)$ \\
$2499 \mathrm{~g}$ & $2.8 \%$ & $4.5 \%$ & $3 \%$ & $3.2 \%$ \\
$>2500 \mathrm{~g}$ & $291(9)$ & $308(15)$ & $136(5)$ & $196(5)$ \\
& $3 \%$ & $5.1 \%$ & $2 \%$ & $2.5 \%$ \\
\hline \hline
\end{tabular}

$\mathrm{A}=$ Admission, $\mathrm{D}=$ Death, $* * \mathrm{p}=\leq 0.05$.

\section{RESUlts}

The cumulative mortality among VLBW infants was $38.5 \%$ at the RH (Table I). Following the introduction of circulatory support and respiratory support by CPAP [4], [5] at the GH (Table II), the mortality rate declined significantly from $40 \%$ in 2012 to $26.5 \%$ in 2013 .

There were clear and positive answers concerning implementation, identification of the primary subjects for the research, description of what was being implemented, and the definition of the implementation strategy. The questions and answers may be found in the supplementary document.

\section{Discussion}

Earlier, we reported weight-related survival at the RH, GH, and J. J. Hospital with the neonatal care package comprising warmth, feeding, antibiotics, oxygen, and circulatory support [9]. The introduction of a simple version of the CPAP system 
led to a sharp decline in mortality (Table II). A study suggests that CPAP coupled with appropriate supportive care may greatly reduce neonatal mortality [10]. There exists a need for a safe, simple-to-use, and affordable bubble CPAP system in LMIC to reduce the need for high-cost mechanical ventilators [11] and mechanical CPAP systems. In this study, a homemade CPAP system [4] was used along with an "aquarium pump", commonly used for pumping air into a fish tank, to blend air and oxygen in the CPAP system [5]. The GH study also illustrates that it is feasible to upscale- interventions and integrate them into the health systems. The upscaling is both horizontal from the $\mathrm{RH}$ model [2] as well as vertical by enhancing the technical capabilities [12].

IR is a subset of health system research that focuses on the acceptance and implementation of evidence-based interventions and policies that have been identified through systematic reviews [13]. Optimal implementation is necessary for the efficacy of the intervention. For the RH study, the two administrative wings of the state government, the Medical Education Department, and the Public Health Department collaborated: an example of participatory action research [3]. The identification, design, and conduct phases of the research, and not just the objectives of the study, were co-created by Grant Medical College, Mumbai, and Rural Hospital, Dahanu, based on a shared commitment to improve neonatal outcomes. The study also gives an example of how to introduce potential solutions to specialized care for newborns into the health system of an LMIC, and to promote their large-scale use and sustainability [13]. As a result, the referral of an LBW baby from the $\mathrm{RH}$ became a rarity.

High neonatal mortality is a wide-spread challenge faced by the global health community. Among newborns in LMIC, such as sub-Saharan Africa, approximately 1 child in 36 dies in the first month, while among the world's high-income countries (HIC), the ratio is 1 in 333 [1]. The estimated average neonatal mortality rate in LMICs is 20 per 1000 live births, while that in HIC is 3 per 1000 births [1]. This indicates a higher availability of know-how and means to reduce neonatal mortality with $\mathrm{HIC}$. Therefore, it is important to implement proven interventions and apply them with appropriate modifications, and at a low cost in the areas with high mortality rates. IR takes what we know and turns it into what we do [12]. The RH component of the study is an example of IR that aims to reduce the knowledge and implementation gap in neonatal health between HIC and LMIC. In the context of this study, the technology transfer was easy from RH to GH. The health staff working in the real world, non-specialist doctors, and nurses are involved and taking part of the evidence, as opposed to it being limited to the people "doing research" [12]. Doing this without additional manpower or budgetary provisions point to realworld settings [3]. The study is conducted under the routine conditions for management and financing with additional budgetary provision, except for the piped oxygen facility, which is to be used by all the departments. It also tests the effectiveness of a package of delivery in the underserved areas carried out with and by local health workers, doctors, and nurses. Moreover, the newborn care model at the RH can be scaled up to offer circulatory support and CPAP, as in the case of the GH, by including VLBW infants. The home-made version of CPAP that has been used [4], maybe mounted by the general duty nurses.

In order to ensure that IR is of high quality, it is important to ask key questions concerning implementation, identification of the primary audiences for the research, clear description of what is being implemented, and a clear definition of the implementation strategy [12]. The basic questions pertaining to the design or reporting of implementation research are answered in the supplementary file.

In summary, there was no difficulty in replicating the program horizontally, from the $\mathrm{RH}$ to $\mathrm{GH}$, and vertically by scaling up the RH model by enhancing circulatory and respiratory capabilities. The limitation of the study is that it was not conducted in the same setting. This was feasible with the addition of manpower, such as resident doctors and nurses with pediatric training. This research also illustrates the powerful potential of IR in developing capacity for FRU for neonatal care in a difficult area of an LMIC, with an option to scale up.

\section{ACKNOWLEDGMENT}

The author thanks Prof. Sanjay Patole of K.E.M. Hospital for Women, University of Western Australia, Perth, for his useful suggestions.

\section{FUNDING}

This research received no specific grant from any funding agency in public, commercial, or not-for-profit sectors.

\section{REFERENCES}

[1] UNICEF. Levels \& Trends in Child Mortality: Report; p. 201, 2017.

[2] Borulkar PD, Borulkar SP, Dhole RK, Daga SR. Special care for newborns at a community hospital: a 5-year experience. Tropical Doctor. 1998; 28(4): 201-203.

[3] Peters DH, Adam T, Alonge O, Agyepong IA, Tran N. Implementation research: what it is and how to do it. BMJ. 2013: 347.

[4] Daga S, Mhatre S, Borhade A, Khan D. (2014). Home-made continuous positive airways pressure device may reduce mortality in neonates with respiratory distress in low-resource setting. Journal of Tropical Pediatrics. 2014; 60(5): 343-347.

[5] Daga BS, Joshi H, Gunjal P, Mhatre S. An innovative air-oxygen blender for continuous positive airway pressure support in resourcepoor locations: A feasibility study. Journal of Tropical Pediatrics. 2017; 63(4): 269-273.6.

[6] Bahl R, Martines J, Bhandari N, Biloglav Z, Edmond K, Iyengar S, et al. Setting research priorities to reduce global mortality from preterm birth and low birth weight by 2015. Journal of Global Health. 2017; 2(1): 7 .

[7] World Health Organization. Safe Motherhood. Thermal Control of the Newborn: a practicalguide.[Internet] 1993. Available from: https://www.who.int/maternal_child_adolescent/documents/ws42097t $\mathrm{h} / \mathrm{en} /$.

[8] Daga S, Naktode N, Borade A, Gawali S. Introducing donor Milk in a neonatal intensive care unit: a developing Country's perspective. The Indian Journal of Pediatrics. 2016; 83(10): 1121-1124.

[9] Daga S, Daga A, Mhatre S, Ghane V. Enhancing neonatal survival: what can we do today? Journal of Perinatology. 2016; 36(8): 681-684.

[10] Kamath BD, MacGuire MSW, Mc Clure EM. Neonatal mortality from respiratory distress syndrome: Lessons for low-resource countries. Pediatrics. 2011; 127: 1139-1146.

[11] Martin S, Duke T, Davis P. Efficacy and safety of bubble CPAP in neonatal care in low- and middle-income countries: a systematic review. Archieves of Disease in Childhood Fetal Neonatal Ed. 2014; 99: F495-504.

[12] Peters DH, Tran NT, Adam T. Implementation research in health: a practical guide. World Health Organization. 2013. 
[13] Sanders D, Haines A. Implementation research is needed to achieve international health goals. PLoS Med. 2006; 3: e186.

[14] Theobald S, Brandes N, Gyapong M, El-Saharty S, Proctor E, Diaz T, et al. Implementation research: new imperatives and opportunities in global health. The Lancet. 2018; 392(10160): 2214-2228. 